\title{
Postmenopausal bleeding: clinicopathologic study in a teaching hospital of Andhra Pradesh
}

\author{
Kavitha Kothapally*, Uma Bhashyakarla
}

Department of Obstetrics \& Gynaecology, Bhaskar Medical College and General Hospital, Yenkapally, Moinabad, Ranga Reddy - 500 075, Andhra Pradesh, India

Received: 11 July 2013

Accepted: 23 July 2013

\section{*Correspondence:}

Dr. Kavitha Kothapally

E-mail: Kavitha.kothapally@gmail.com

(C) 2013 Kothapally K et al. This is an open-access article distributed under the terms of the Creative Commons Attribution Non-Commercial License, which permits unrestricted non-commercial use, distribution, and reproduction in any medium, provided the original work is properly cited.

\section{ABSTRACT}

Background: Postmenopausal bleeding (PMB) requires complete assessment in order to ensure the absence of malignancy and to identify and treat high risk patients such as those with endometrial hyperplasia. The aim of the present study was to investigate the clinical significance and endometrial pathology in patients with postmenopausal bleeding.

Methods: A retrospective study on postmenopausal women visiting Bhaskar Medical College \& general hospital, Yenkapally, Andhra Pradesh between 2009-2011 was undertaken. About 30 patients (aged between 50-60 years) with postmenopausal bleeding were selected and these patients were evaluated by curettage, pelvic ultrasound and endometrial histology.

Results: The commonest finding of pelvic USG was increased endometrial thickness $(>4 \mathrm{~mm})(80 \%)$. The histopathological analysis showed proliferate endometrium (36.3\%), atrophic endometrium (16.6\%), cystoglandular hyperplasia (10\%) and endometrium hyperplasia (6.6\%). Incidence of cervical and endometrial carcinomas was $10 \%$ and $6.6 \%$, respectively.

Conclusion: the postmenopausal bleeding is an important symptom and requires careful and timely assessment to eliminate the possibility of malignancy as soon as possible.

Keywords: Postmenopausal bleeding, Endometrial thickness, Pelvic ultrasound

\section{INTRODUCTION}

WHO defines menopause as permanent cessation of menstruation resulting from loss of ovarian activity. ${ }^{1}$ Postmenopausal bleeding (PMB) is defined as abnormal uterine bleeding occurring after 1 year of menopause. Common menopausal age in Indians is 4550 years. Postmenopausal women constitute only $1 \%$ of female population. Postmenopausal bleeding represents one of the most common reasons for referral to gynaecological services, largely due to suspicion of an underlying endometrial malignancy. ${ }^{2}$ A woman not taking hormone replacement therapy (HRT) who bleeds after the menopause has a $10 \%$ risk of having genital cancer and a further $10 \%$ risk of significant pathology. ${ }^{3}$ Therefore, postmenopausal bleeding should always be investigated no matter how minimal or non-persistent.

Etiology of post-menopausal bleeding include: nongynaecological causes like trauma or a bleeding disorder, use of hormone replacement therapy, vaginal atrophy, endometrial hyperplasia (simple, complex, and atypical), endometrial carcinoma usually presents as PMB but $25 \%$ occur in premenopausal women. Other causes include endometrial polyps or cervical polyps, carcinoma of 
cervix, uterine sarcoma, ovarian carcinoma (especially oestrogen-secreting ovarian tumours), vaginal carcinoma which is very uncommon \& carcinoma of vulva may bleed, but the lesion should be obvious. ${ }^{3-7}$

Ultrasound pelvis is an appropriate first-line procedure to identify which woman with post-menopausal bleeding is at higher risk of endometrial cancer. In general, the thicker the endometrium, the higher the probability of important pathology i.e. endometrial cancer being present. Hysteroscopy and biopsy (curettage) is the preferred diagnostic technique to detect benign lesions. As such there are several investigations available to complement clinical evaluation, including ultrasound, endometrial histology and hysteroscopy to evaluate the underlying etiology of PMB. ${ }^{8-12}$

A number of studies on clinical evaluation of PMB in postmenopausal women have been conducted worldwide, but there are few reports from India and none from rural setup hospital to determine the problem and the risks in the rural population. So this study was aimed to present a hospital-based survey, to investigate the clinical significance of postmenopausal bleeding in terms of etiology, risks factors, incidence of malignancy, and histopathological evaluation.

\section{METHODS}

This retrospective study was done at Bhaskar Medical College and General Hospital, Andhra Pradesh between January 2009 - December 2011 in the Department of Obstetrics \& Gynecology in collaboration with Department of Pathology \& Radiology. Out of 600 gynecology patients attending OPD per month, a total of 30 cases who presented clinically with postmenopausal bleeding were selected. All the patients gave history of genital tract bleeding varying from spotting per vagina, scanty flow, moderate to profuse bleeding.

The age of the patients was recorded. Full assessment done by history, physical examination $\&$ investigations which include complete blood picture, fasting blood sugar \& pelvic ultrasound. Pap smear and diagnostic curettage were performed. The specimens from endometrial biopsy/curettage were sent for histopathological evaluation. The slides were reviewed and classified using current pathological criteria.

The endometrial specimens were divided into the following histological categories: atrophy; proliferation; secretion; endometrial poly; simple or cystic hyperplasia; adenomatous hyperplasia; atypical hyperplasia; carcinoma and others. Measurement of endometrial thickness by pelvic ultrasound having a cut-off of $>4 \mathrm{~mm}$ yields $98 \%$ sensitivity for detection of endometrial cancer. The present study was approved by our institutional ethics board. Values are given as percentage (\%). We used the statistical software SPSS 10.0 for
Windows (SPSS 10.0, SPSS Inc., Chicago, IL) for the analysis.

\section{RESULTS}

Patients' characteristics of PMB patients are shown in Table 1. Most of postmenopausal bleeding patients were between 50-60 years (56.6\%) and were multiparous (90\%). $36.6 \%$ and $43.3 \%$ of patients were having hypertension and overweight, respectively. $13.3 \%$ of women were suffering from diabetes mellitus.

Table 1: Distribution of age, parity and medical history of menopausal women.

\begin{tabular}{|c|c|c|}
\hline & $\begin{array}{l}\text { No. of } \\
\text { patients } \\
(\mathrm{N}=30)\end{array}$ & $\begin{array}{l}\text { Percentage } \\
(\%)\end{array}$ \\
\hline \multicolumn{3}{|c|}{ Age of menopause (yrs) } \\
\hline $40-45$ yrs & 04 & $13.3 \%$ \\
\hline $45-50$ yrs & 13 & $43.3 \%$ \\
\hline$>50 \mathrm{yrs}$ & 13 & $43.3 \%$ \\
\hline \multicolumn{3}{|c|}{ Age of postmenopausal bleeding (yrs) } \\
\hline $45-50 \mathrm{yrs}$ & 05 & $16.6 \%$ \\
\hline $50-60 \mathrm{yrs}$ & 17 & $56.6 \%$ \\
\hline$>60 y r s$ & 04 & $13.3 \%$ \\
\hline \multicolumn{3}{|l|}{ Parity } \\
\hline Nullipara & 02 & $6.7 \%$ \\
\hline Para2 & 01 & $3.3 \%$ \\
\hline$>$ para & 27 & $90 \%$ \\
\hline \multicolumn{3}{|l|}{ Medical disease } \\
\hline Hypertension & 11 & $36.6 \%$ \\
\hline Diabetes mellitus & 4 & $13.3 \%$ \\
\hline $\begin{array}{l}\text { Overweight (50- } \\
100 \mathrm{~kg})\end{array}$ & 13 & $43.3 \%$ \\
\hline Obesity (>100kg) & 0 & $0 \%$ \\
\hline Hypothyroidism & 1 & $3.3 \%$ \\
\hline No illness & 1 & $3.3 \%$ \\
\hline Hormonal intake & 0 & $0 \%$ \\
\hline
\end{tabular}

The pelvic USG showed endometrial thickness of $>4 \mathrm{~mm}$ in majority of cases $(80 \%) \&$ none had adnexal masses. $15 \%$ women had endometrial polyps. The uterine abnormalities observed are bicornuate uterus, pyometra and hematometria (Figure 1).

From Figure 2, the fractional curettage showed that curettings were scanty in most of the cases in spite of thick endometrium. 


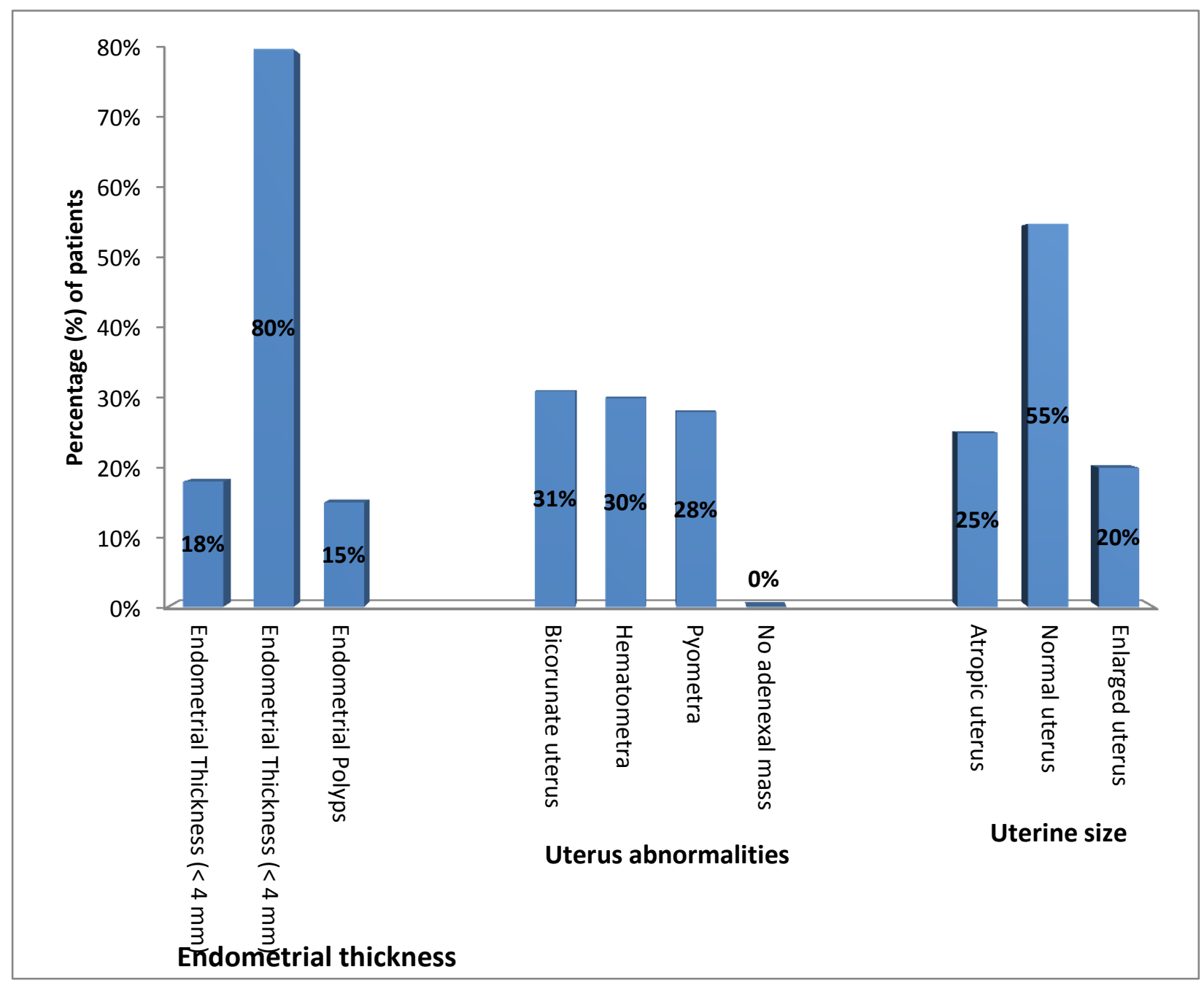

Figure 1: Pelvic ultrasound findings of post menopausal bleeding patients.

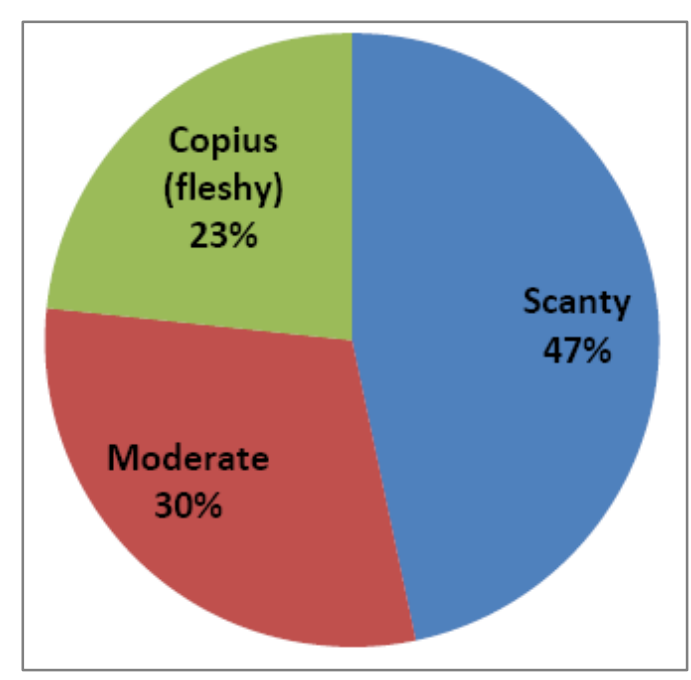

Figure 2: Types of uterine curettings.
Table 2: Histopathological findings of endometrium.

\begin{tabular}{|l|l|l|}
\hline $\begin{array}{l}\text { Histopathological } \\
\text { findings }\end{array}$ & $\begin{array}{l}\text { No. of } \\
\text { patients } \\
(\mathbf{n = 3 0})\end{array}$ & $\begin{array}{l}\text { Percentage } \\
(\%)\end{array}$ \\
\hline Proliferative & 11 & $36.3 \%$ \\
\hline Atrophic & 5 & $16.6 \%$ \\
\hline $\begin{array}{l}\text { Cystoglandular } \\
\text { hyperplasia }\end{array}$ & 3 & $10 \%$ \\
\hline Endometrial hyperplasia & 2 & $6.6 \%$ \\
\hline Endometritis & 2 & $6.6 \%$ \\
\hline Endometrial polyp & 1 & $3.3 \%$ \\
\hline Cervical carcinoma & 3 & $10 \%$ \\
\hline Endometrial carcinoma & 2 & $6.6 \%$ \\
\hline Fibroids & 1 & $3.3 \%$ \\
\hline
\end{tabular}


According to table 2, the common histopathology of endometrium was proliferative $(36.3 \%)$, next common being atrophic endometrium $(16.6 \%)$ \& cystoglandular hyperplasia $(10 \%)$. Other findings include endometrial hyperplasia $(6.6 \%)$, endometrial polyps $(3.3 \%)$, cervical carcinoma (10\%) and endometrial carcinoma (6.6\%).

\section{DISCUSSION}

Postmenopausal bleeding is a sinister complaint of postmenopausal women. It is common between 5-10yrs after reaching menopause and common age predilection is between 50-60 yrs. Beyond this age, endometrial malignancy is more common. The peak incidence of malignancy was observed in the age group of 55-64 years. ${ }^{13}$ Post menopausal bleeding has been evaluated by clinical examination, pelvic ultrasound, investigations like pap smear $\&$ fractional curettage in this study.

Most of PMB patients were multiparous (>3) associated with medical illnesses like HTN, DM \& obesity. Pap smear performed routinely didn't yield any benefit in diagnosing the etiology of PMB. Pelvic USG showed endometrial thickness of $>4 \mathrm{~mm}$ in majority of cases \& none had adnexal masses.

Regarding fractional curettage, most of cases showed that the curettings were scanty in spite of thick endometrium. This aberration may be due to endometrial polyps on the thick endometrium \& these polyps may not be amenable to blind curettage.

The common histopathology of endometrium was proliferative, next common being atrophic endometrium \& cystoglandular hyperplasia. With reference to carcinoma, 3 patients were diagnosed as cervical carcinoma and 2 patients with endometrial carcinoma.

Commonest findings was proliferative endometrium, which suggests a high level of unopposed oestrogen stimulation, this can be endogenous or exogenous and lead to rapid progression to endometrial hyperplasia or cancer. $^{14}$

In this study, the second commonest findings was atrophic endometrium ( $16.6 \%$ ) among other benign pathologies, which was also observed in previous studies by Caspi E et al ${ }^{15}$ and Bani-Irshaid I and Al-Sumadi A. ${ }^{16}$ The exact cause of bleeding from atrophic endometrium is not known. It is postulated to be due to anatomic vascular variations or local abnormal haemostatic mechanism. $^{17-18}$

Endometrial polyp (15\%) \& endometrial hyperplasia $(6.6 \%)$ were the other frequent causes of PMB in our study. These results are similar to those found by Bafna et.al. (2006) where endometrial polyp \& endometrial hyperplasia constituted one of the causes of postmenopausal bleeding. ${ }^{19}$
Moreover, the incidence of endometrial adenocarcinoma and carcinoma cervix was $6.6 \%$ and $10 \%$ respectively, which was much lower than the earlier studies done by Escoffery et $\mathrm{al}^{5}$ and Udiqwe et al. ${ }^{20}$ This might be due to less sample size or insufficient tissue for histopathological diagnosis.

The patients of this study were treated accordingly, PMB was managed conservatively for atrophic endometrium or endometritis or benign endometrial polyps. Whereas, precancerous histopathologies like cystoglandular hyperplasia, atypical hyperplasia, and complex hyperplasia were subjected to hysterectomy. About 6 patients underwent hysterectomy. Patients with malignancy were referred to cancer hospital for further management. Simple endometrial hyperplasia/ proliferative endometrium were put under observation for recurrent episodes of bleeding.

Finally, our study was consistent with the previously published studies regarding the etiologies and risk factors associated with PMB. Hence, regular follow-up of all women for a longer period of time may detect more women harbouring endometrial cancer or hyperplasia, when they experience recurrent PMB. Such a policy may improve the ability to predict these diseases. Our study had limitations, namely the retrospective study design, the extraction of information from patients' files, the relatively less number of patients, and the relatively short time of follow up. Therefore a large sample size study with long term follow-up is required to establish the etiology, risks factors, incidence of malignancy and prognosis of the patients.

\section{CONCLUSION}

Women with a thick endometrial thickness ( $>4 \mathrm{~mm}$ ) or histopathology showing a proliferative at the initial assessment are especially at risk. A more thorough examination and specific management should be carried out for a woman who presents with PMB and increased endometrial thickness using hysteroscopic assessment and other investigations. Women with recurrent PMB after an initial negative assessment should be reinvestigated because they may still have significant genital tract pathology.

Funding: No funding sources

Conflict of interest: None declared

Ethical approval: The study was approved by the Institutional Ethics Board

\section{REFERENCES}

1. W.H.O. Research on the menopause in the 1990s. Report of a WHO Scientific Group. World Health Organization technical report series 1996;866:1-107.

2. Hawwa ZM, Nahhas WA, Copenhaver EH. Postmenopausal bleeding. Lahey Clinic Foundation Bulletin 1970; 19:61-70. 
3. Astrup K, Olivarius Nde F. Frequency of spontaneously occur ring postmenopausal bleeding in the general population. Acta Obstetricia et Gynecologica Scandinavica 2004; 83(2):203-7.

4. Ronghe R, Gaudoin M. Women with recurrent postmenopausal bleeding should be re-investigated but are not more likely to have endometrial cancer. Menopause International 2010;16(1):9-11.

5. Escoffery CT, Blake GO, Sargeant LA. Histopathological findings in women with postmenopausal bleeding in Jamaica. West Indian Medical Journal 2002;51(4):232-5.

6. Gredmark T, Kvint S, Havel G, Mattsson LA. Histopathological findings in women with postmenopausal bleeding. British Journal of Obstetrics and Gynaecology 1995;102(2):133-6.

7. Lee WH, Tan KH, Lee YW. The aetiology of postmenopausal bleeding-a study of 163 consecutive cases in Singapore. Singapore Medical Journal. 1995;36(2):164-8.

8. Kaur M, Singh R, Sharma M. Endovaginal sonographic evaluation of postmenopausal uterine bleeding. Journal of Clinical \& Diagnostic Research 2010;(4):2175-82.

9. Ferrazi E, Torri V, Trio D, Zannoni E, Filiberto S, Doedoni D. sonographic endometrial thickness: a useful test to predict atrophy in patients with postmenopausal bleeding. Italian multicenter study. Ultrasound in Obstetrics and Gynecology 1996;7;315-21.

10. Sahdev A. Imaging the endometrium in postmenopausal bleeding. British Medical journal 2007;334(7594):635-6.

11. Smith-Bindman R, Weiss E, Feldstein V. How thick is too thick? When endometrial thickness should prompt biopsy in postmenopausal women without vaginal bleeding. Ultrasound in Obstetrics and Gynecology 2004;24(5):558-65.
12. Gupta JK, Chien PF, Voit D, et al. Ultrasonographic endometrial thickness for diagnosing endometrial pathology in women with postmenopausal bleeding: a metaanalysis. Acta Obstetricia et Gynecologica Scandinavica 2002 Sep;81(9):799-816.

13. Breijer MC, Timmermans A, van Doorn HC, Mol BW, Opmeer BC. Diagnostic strategies for postmenopausal bleeding. Obstetrics and Gynecology International 2010;2010:850812. doi: $10.1155 / 2010 / 850812$.

14. Pl So, Wk Sin, Hc Lee, Kc Au Yeung. Evaluation of Recurrent Postmenopausal Bleeding. Hong Kong Journal of Gynaecology, Obstetrics and Midwifery 2012;12(1):69-79.

15. Caspi E, Perpinial S, Reif A. Incidence of malignancy in Jewish 13. Women with postmenopausal bleeding. Israel Journal of Medical Sciences 1977;13(3):299-304.

16. Bani-Irshaid I, Al-Sumadi A. Histological findings in women with postmenopausal bleeding: Jordanian figures. Eastern Mediterranean Health Journal 2011;17(7):582-86.

17. Fortier KJ. Postmenopausal bleeding and the endometrium. Clinical Obstetrics and Gynecology 1986;29:44-5.

18. Gredmark T, Havel G, Mattsson L-A. Histopathological findings 15 . in women with postmenopausal bleeding. British Journal of Obstetrics and Gynaecology 1995;102(2):133-6.

19. Bafna UD, Shashikala P. Correlation of endometrial ultrasonography and endometrial histopathology in patients with postmenopausal bleeding. Journal of the Indian Medical Association 2006;104(11):627-9.

20. Udigwe GO, Ogabido CA. A clinico-pathological study of cervical carcinoma in South Eastern Nigeria; a five-year retrospective study. Nigerian Journal of Clinical Practice 2008;11(3):202-5.

DOI: $10.5455 / 2320-1770 . i j \operatorname{cog} 20130916$

Cite this article as: Kothapally $\mathrm{K}$, Bhashyakarla $\mathrm{U}$. Postmenopausal bleeding: clinicopathologic study in a teaching hospital of Andhra Pradesh. Int J Reprod Contracept Obstet Gynecol 2013;2:344-8. 